\title{
Futebol e cinema: relações
}

Victor A. de Melo

https://doi.org/10.5628/rpcd.06.03.362
U niversidade Federal do Rio de Janeiro

Brasil
RESUMO

Este artigo tem por objetivo discutir as relações entre futebol e cinema no decorrer da história, bem como identificar representações deste esporte em filmes, de forma a entender uma das vias de sua popularização. A despeito de fatores limitantes e de muitos desafios, o estudo reconhece que o futebol esteve presente na obras de importantes cineastas e em al gumas cinematografias mundiais. Só no Brasil, entre 4.500 películas analisadas e entre 204 filmes que de al guma forma representam o esporte, o futebol está presente em 117 produções. Nesse percurso, cinema e futebol se influenciaram mutuamente, al go que permite a pesquisadores entender melhor certos discursos sobre a sociedade.

Palavras-chave: futebol, cinema, história do esporte

\section{ABSTRACT \\ Soccer and Cinema: relations}

This article has for objective to discuss the relations between soccer and cinema in history, as well to identify representations of this sport in films, trying to understand better one of the ways of its spreading. A Itough we can observe certain difficulties and many challenges, the study recognizes that the soccer was present in the movies of important directors and in some world-wide cinematographies. In Brazil, between 4.500 analyzed films and between 204 movies that have some form of representation of sport, the soccer is present in 117 productions. In this historical development, cinema and soccer had influenced each other, something that allows the researchers to better understand certain speeches on the society.

Key-words: soccer; cinema; sport history 


\section{INTRODUÇÃO}

Na sociedade contemporânea, o futebol praticamente se impõe em cada pedaço desse mundo globalizado. Não surpreende, portanto, o fato de que haja mais países ligados à Federação Internacional de Futebol (FIFA) do que à Organização das Nações Unidas (ONU). Outro indício interessante: os maiores índices mundiais de audiência televisiva são obtidos exatamente por ocasião da realização das Copas do Mundo. Somente considerando o sorteio dos grupos para a edição de 2006, 145 países receberam as imagens e aproximadamente 320 milhões de espectadores acompanharam a definição das partidas.

Se o futebol é uma grande paixão mundial, o cinema não é um amor menor. Os heróis e heroínas, os vilões e vilãs, as estrelas cinematográficas e seus comportamentos inundam o nosso imaginário. Hábitos e costumes, valores e sensibilidades, formas de ser e de se portar, ocorrências históricas, utopias e sonhos difundidos pelas películas e pelo circuito construído ao redor dessa jovem arte, herdeira direta da modernidade, habitaram o cotidiano de pessoas de todo o mundo: nada parece ter passado desapercebido aos cineastas e seus filmes.

Assim, quando discutimos as relações entre futebol e cinema, estamos certamente narrando os encontros e desencontros entre duas paixões universais, diferentes mas profundamente relacionadas. Na verdade, os encontros entre o esporte (e o futebol é hoje o principal representante mundial dessa manifestação cultural) e o cinema não são ocasionais (1). Vale destacar que são fenômenos típicos da modernidade (ainda que possuam raízes anteriores), se organizando a partir das mudanças culturais, sociais e econômicas observáveis desde o fim do século XVIII e no decorrer do século XIX. Ambos constituem-se como poderosas representações de valores e desejos que permeiam o imaginário do século XX: a superação de limites, o extremo de determinadas situações, a valorização da tecnologia, a consolidação de identidades nacionais, a busca de uma emoção controlada. Ambos celebraram e foram celebrados pelas novas dimensões de vida e de sociedade construídas no decorrer do século que passou (2).

Este artigo objetiva discutir as peculiaridades dos relacionamentos entre essas duas artes, esses dois fenômenos, essas duas paixões. Sua principal justifi- cativa é permitir um melhor entendimento de uma das formas de difusão do fenômeno esportivo, o cinema, al go diretamente relacionado à própria modernidade e constituição da sociedade da imagem e do consumo (3).

\section{O FUTEBOL NO CINEMA MUNDIAL}

Copiar una obra de arte es imposible; intentarlo es más factible, aunque en el resultado final queda siempre la evidencia de nunca poder mostrar el alma del autor. Al final es uma copia inexacta. A lgo así debe ocurrir entre el desencuentro del cinema y el fútbol; dos artes segúns se mire com alma propia sin comparación (4).

Vamos discutir de imediato uma questão que sempre vem à baila quando se discute a presença do futebol no cinema: por que tão pouca presença do velho esporte bretão nas películas produzidas por todo mundo, inclusive em países nos quais goza de grande popularidade, como o Brasil e a Itália? Se são constantes e profícuos os encontros entre cinema e esporte, por que a mais popular das práticas esportivas contemporâneas está em certo sentido pouco representada, ainda mais quando a comparamos a outros esportes, como o boxe (este quase um gênero à parte entre os filmes esportivos)? Alguns motivos podem ser elencados:

\section{Questões técnicas}

Ao contrário do boxe, da natação e de alguns outros esportes, é muito difícil recriar artificialmente uma partida de futebol. Mesmo que encontrássemos um bom jogador de futebol que também representasse bem, algo pouco provável, é muito difícil recriar com exati dão as inusitadas e imprevisíveis situações de um jogo, um dos encantos, al iás, deste esporte. Ao contrário das películas, que são obras de arte produzidas a partir de um certo controle, até mesmo em função de suas características (normalmente, por exemplo, há um roteiro prévio), uma partida de futebol é bastante aberta, uma performance sem roteiro pré-definido (ainda que existam as "jogadas ensaiadas"), onde um grande número de variáveis interfere na configuração do resultado final (5).

Para solucionar este problema, os cineastas fizeram uso de recursos diversos: recriaram partidas mes- 
clando atletas profissionais com atores; editaram cenas de jogos "reais" com as de "cenográficos"; fizeram uso de muitos planos detal hes nos corpos dos jogadores ou planos gerais do gramado; tentaram ensaiar jogadas; extrapolaram ao máximo a trama para além das linhas do gramado. Todas, em mai or ou menor grau, fracassaram na tentativa de reproduzir o esporte. Mesmo que o avanço tecnológico tenha minimizado essas dificuldades, ainda se está longe de uma solução eficaz.

Também por isso, não é incomum que os filmes de futebol não obtenham expressivos resultados de bilheteria, atraindo pouco o público que vai aos está dios. O torcedor, acostumado a dinâmica das quatro linhas, não se satisfaz com o que vê na tela. Isso ajuda também a explicar o porquê do grande número de filmes documentais produzidos, majoritariamente para o mercado doméstico, onde se apresentam coletâneas de belos gols, belas jogadas, fatos inusitados do esporte. Na verdade, também para as salas de projeção se produziu e continua a se produzir esse tipo de películar.

Este material de natureza documental, que historicamente é anterior aos filmes de ficção, tem sido de grande importância para contribuir para a difusão do futebol por todo o mundo, notadamente a partir da construção de mitos: os grandes jogadores do passado, os jogos inesquecíveis; a mística que envolve o esporte, algo que passa necessariamente pela torcida, uma de suas facetas fundamentais².

Aliás, uma das mais importantes iniciativas documentais relacionadas ao futebol é de origem brasileira: o Canal 100, um capítulo à parte nas relações entre futebol e cinema. Produzido entre os anos de 1959 e 1986, nesse cinejornal o futebol ocupava lugar de grande importância e era exibido como nunca antes o fora no país, elevado à categoria de um épico. Há indícios que demonstram que mesmo mundialmente as imagens esportivas produzidas pela equipe do Canal 100 estavam entre as mais belas. Tanto assim que a produtora ganhou a concorrência de exclusividade para a captação de imagens na Copa do Mundo de $1970(6,7)$.

\section{Dramas}

Ainda que a figura do craque seja de grande importância para o futebol, este é um esporte coletivo, onde 22 pessoas (além dos árbitros) interagem todo o tempo. Com isso, e pelo que o envolve fora de campo, possui uma força dramática menos explícita do que, por exemplo, o boxe.

Os esportes individuais permitem exponenciar os embates típicos do cinema, notadamente construídos a partir de uma dualidade maniqueísta: um herói e um bandido, o primeiro sempre se superando para enfrentar o segundo. Além disso, ainda que o futebol seja um jogo violento, esta dimensão não fica tão clara quanto no boxe, onde é sempre a tônica. Violência, sangue, suor são peças de grande valia para a composição de histórias notáveis.

Menor interesse do público norte-americano A principal indústria cinematográfica mundial ainda é a dos Estados Unidos. Como o público norte-americano tem menor interesse pelo "soccer", isso também influencia na realização de um número menor de filmes onde o futebol está presente.

De qual quer forma, a despeito de todos esses fatores, não se pode dizer que o futebol não esteve presente nas telas. No cinema espanhol, por exemplo, o estudo de Joaquim Ramió (8) levanta cerca de 65 presenças nas telas grandes, sendo de 1915 o primeiro curta-metragem (Clarita y Peladilla van al Fútbol, de Benito Perojo) e de 1929 o primeiro longa (Fútbol , A mor y Toros, de Florián Rey).

Entre esses filmes, podemos destacar a participação como ator do grande jogador Alfredo Di Stefano (por exemplo, no filme Saeta Rubia, 1956, dirigido por Javier Setó), películas sobre o cotidiano do esporte (como o pioneiro !!C ampeones!!, 1942, de Ramon Torrado) e os mais recentes El Portero (2000, de Gonzalo Suárez) e Días de fútbol (2003, de David Serrano), bastante premiada e que manteve-se por um ano entre os 3 mais assistidos na Espanha. Sobre a cinematografia portuguesa, conseguimos obter dados sobre al guns filmes recentes. Entre as que se destacam está o longa Tudo isto é fado (2003, Luis Galvão Teles), uma co-produção com o Brasil, que conta a história de dois malandros que conseguem sucesso somente em função da Copa do Mundo da França; curioso é o paralelo entre a arte como um todo e a mais popular das artes: o futebol. Outro filme de sucesso e elogiado foi És a nossa fé (2004, Edgar Pêra), um documentário curta-metra- 
gem, uma reflexão sobre fãs do futebol e a constituição do esporte enquanto espetáculo de massas, enquanto algo que encanta multidões.

Bastante premiado e exibido em muitos países, há que se destacar ainda Finta o destino (1998, Fernando Vendrell), sobre os sonhos, frustrações e desejos de um ex-jogador de futebol de Cabo Verde, outrora famoso em seu país. O filme é bastante interessante não só por discutir a questão central dos ídolos do passado, como também pela abordagem sensível das relações de Portugal com suas ex-colônias.

Aliás, vale a pena citar A bola, um curta de Orlando Mesquita (2002), de Moçambique, país em que no passado houve uma forte tradição cinematográfica. $\mathrm{O}$ filme compõe uma fábula a partir do fato real de que, em sua nação, crianças usam preservativos para a prática do futebol. Devemos certamente no futuro investigar com mais cuidado a cinematografia dos países de língua portuguesa.

Assim como em Portugal, mundialmente nos últimos anos vemos surgir um número maior de filmes onde o futebol está presente. Por exemplo, entre outros, Febre de Bola (David Evans, 1997), A Copa (Khyentse Norbu, 1999), D riblando o destino (Gurinder Chadha, 2002) e as animações japonesas Super Campeões- volume 1 e 2 (2002), sobre um garoto que sonhava em vir para o Brasil e se tornar grande jogador.

É interessante identificar o lugar que o Brasil (sejam seus jogadores ou seus símbolos) ocupa em muitas dessas películas, ainda que de forma bastante estereotipada. Parece um mistério que al guns cineastas desejam entender: a qualidade e vigor do futebol brasileiro; quase um ato de reverência. Essa referência aparece, por exemplo, em M eu nome é Joe (1998), um belo e poético filme do grande cineasta inglês Ken Loach. Ao dirigir seu sensível e crítico ol har para o "submundo" dos desempregados escoceses, o diretor tem como protagonista um alcoólatra que treina o pior time de futebol da região, que joga com uma camisa que faz menção à seleção brasileira.

Outro filme bastante denso é Footbal Factory (2004, direção de Nick Love), cujo personagem central é um jovem hooligan, Tommy Johnson, torcedor do Chelsea; um verdadeiro estudo sobre o papel do futebol na vida cotidiana, sobre a construção de uma cultura masculina, sobre a violência. Longe dos purismos que cercam muitos discursos sobre o esporte, o vemos plenamente inserido no contexto social, ao lado de sexo, drogas, álcool.

Vale ainda referência a 0 M edo do Goleiro diante do Pênalti (1971), do diretor alemão Win Wenders, baseado no romance de Peter Handke. O filme narra a história de Josef Bloch, um goleiro de uma equipe da segunda divisão, expulso de uma partida por cometer uma falta. Pela noite ele mata a atendente de cinema com a qual sai e foge para a casa de uma amiga, de onde acompanha, aparentemente de maneira desinteressada, a perseguição da polícia, que o captura em um estádio de futebol. Mesmo que não haja muito do esporte na trama, vale pelo destaque que tem para desencadear o drama. Como não temos espaço para comentar todos esses filmes, nos aprofundaremos em um dos mais rele vantes que tentou levar o futebol para as grandes telas: Fuga para a Vitória (1981), dirigido por John Huston, estrelado por grandes nomes do cinema (como Sylvester Stallone e Michael Caine) e do futebol (como Pelé e Bobby Moore).

Esta película merece destaque pela força dramática do enredo e por ser bastante interessante para discutirmos a presença social do futebol, a partir de suas relações com o cinema. O pano de fundo da trama é um jogo disputado, na Segunda Grande Guerra, entre o selecionado alemão e uma equipe de prisioneiros de guerra (liderada pelo capitão inglês John Colby). o que era a princípio uma atividade local (uma brincadeira, um "jogo de várzea”, proposta do major Karl Von Steiner) vai se transformando em um evento, uma disputa si mbólica de enorme vulto. Os al emães desejam vencer a todo custo para provar a supremacia do regime nazista; os presos querem aproveitar a situação para fugir.

$\mathrm{Na}$ verdade, é difícil ver o filme e não lembrar da famosa frase de Bill Shankly, técnico do Liverpool nos anos 60: "o futebol não é uma questão de vida ou morte; é muito mais do que isso". No caso da película, isso é levado literalmente ao pé da letra. Os paral elos entre "vida" e "jogo", entre "esporte" e "guerra", entre "resultados" e "honra" permeiam todo a trama.

Inspirado em episódio real, esse aparentemente banal roteiro acaba tocando, ora mais ora menos intencionalmente, em muitas questões: o uso políti- 
co do futebol; o esporte como propaganda; a imprevisibilidade do jogo; as falcatruas do campo esportivo; os privilégios dos atletas; as desigualdades que podem interferir nos resultados; o importante papel da torcida; a questão da honra, do companheirismo, da superação; os limites da liberdade.

$O$ argumento central é resumidamente bem captado por Gonzalez (9):

Como pudo demostrar este guión y este argumento, el fútbol es um estado de igualdad, en el que cualquiera puede aspirar a ser mejor com diferentes armas. A quí no se utilizaban las agresivas y convencionales, se pretendían hacer daño con lo que más duele: sin violencia y con la inspiración.

Mesmo que do ponto de vista da análise sociológica esta afirmação seja polêmica, não podemos negar que é um discurso corrente, reforçado, portanto, neste e em outros casos, pelo cinema.

John Huston, experimentado e premiado cineasta, ainda que não fosse muito ligado ao futebol, soube enfrentar os desafios de transpor este esporte para as telas. Para dar conta das questões técnicas usou ao máximo cada elemento de sua equipe, compondo um "mix" entre jogadores e atores.

Como uma grande parte do filme não se passa nos gramados (e isso já é em si uma estratégia narrativa), pouco se vê da atuação dos jogadores como atores (e quando isso ocorre, é bastante deficiente do ponto de vista dramatúrgico). N esse caso, procurou compensar com as estrelas do cinema norte-americano.

Para as cenas de futebol, contou com a contribuição de Pelé na preparação das "coreografias" dos treinos e da partida. Por si só a presença do "rei do futebol", sempre encantado e envolvido com o cinema, como se soubesse de sua importância para construir o mito a seu redor (10), já pode ter funcionado como chamariz de público.

Obviamente devemos considerar que Huston encarou o limite tão bem apontado por José Gonzalez (11): "por sí solo el fútbol es inimitable e irreproducible. Como el cine". Por exemplo, é pouco factível Sylvester Stallone representando o papel de goleiro da equipe dos prisioneiros, ainda que Huston tenha procurado também lidar com isso, já que o personagem era apresentado como "perna de pau", nunca tendo atuado antes como goleiro e só participando da par- tida em função das injunções do plano de fuga. O diretor, buscando desencadear emoções ao redor da partida, soube de forma adequada recriar al go muito comum nos filmes de boxe: uma composição claramente maniqueísta, onde ficam bem marcados os papéis de heróis (prisioneiros) e bandidos (alemães nazistas), ainda que com matizes de ambos os lados (pequenas fragilidades de caráter de al guns presos e sentimento de "nobreza esportiva" do major al emão Steiner, algo que supostamente trouxera de sua experiência como ex-jogador de futebol). Ao recorrer a esse recurso, torna mais eficaz o recriar de estruturas dramáticas desenvolvidas pelo cinema norte-americano no decorrer de sua história.

Aliás, vale lembrar que Huston fora boxeador na sua juventude e trabal hara como jornal ista esportivo durante alguns anos. Foi também diretor de películas onde a "nobre arte" ocupava lugar central, como Cidade das Ilusões (1972). Com isso quero argumentar que uma das estratégias do di retor de Fuga para a Vitória foi aproximá-lo das estruturas dos filmes de pugilismo, que em função de suas características é um esporte mais adequado para o formato da narrativa cinematográfica mais tradicional.

Fuga para a Vitória, sem ser um filme inesquecível, é um bom exemplo de como al gumas temáticas estiveram presentes nas oportunidades em que o futebol freqüentou as grandes telas: o jogo enquanto metáfora da vida; das tensões entre desencanto e superação; como forma de controle e também de resistência; como mecanismo de desilusão, assim como de êxtase; como retrato das múltiplas dimensões que compõe um ser humano e a sociedade na qual vive. Antes de encerrar esse item, gostaria de proceder uma última discussão. Normal mente fazemos uma ligação direta entre o futebol e o jogo no qual 11 jogadores de cada lado tentam fazer a bola penetrar na meta adversário, fazendo para isso uso exclusivo dos pés (com exceção do goleiro, autorizado a usar as mãos). Mas, lembremos, existem muitos outros "futebóis" pelo mundo, que também gozam de grande popularidade.

Entre os mais populares temos o rugby e o futebol americano, que também já inspiraram muitas pelícuIas. Entre elas, Duelo de Titãs (2000, de Boaz Yakin), com Denzel Washington no papel principal; e Jerry M aguire (1996, dirigido por Cameron Crowe), estrelada por Tom Cruise. 
Aliás, lembremos que existe um enorme número de outras formas de manifestação do futebol: em jogos populares infantis ("rebatida”, "cascudinho", "golzinho", “disputa de embaixadinhas"), em brinquedos ("Jogo de Peteleco"; "Jogo de Preguinho", "Jogo de Chapinha" "Totó ou Pebolin"), em vídeo-games ("Fifa Soccer", "Championship Management"). O futebol também está presente na música, na poesia, nas crônicas, nas obras de arte, na dança. Está presente em todos os espaços de nossa vida cotidiana. Assim sendo: por que não estaria no cinema?

\section{O FUTEBOL NO CINEMA BRASILEIRO}

"Garrincha, alegria do povo", documentário sobre o futebol brasileiro, é antes de tudo visão do povo, do amor do povo, da miséria, da alegria, da superstição e da grandeza do povo na figura do menino das pernas tortas, que é 0 improviso do povo (12).

E no "país do futebol", como o cinema representou o futebol? No Brasil freqüentemente também vemos surgir a discussão de que temos poucos filmes sobre o assunto. Já aprofundei um pouco tal discussão em outros momentos (13) e aqui quero ir direto ao ponto: isso não é verdade.

De fato, o que há é um desconhecimento de nossa produção cinematográfica, uma restrição na consideração somente dos longa-metragens e uma comparação infundada com outros países: de nada adianta contrastar com outros esportes nos Estados Unidos, por exemplo; lá, na verdade, há mais filmes de qualquer tema.

Segundo o levantamento que real izamos em mais de 4.500 longas brasileiros, entre 204 que de alguma forma representam o esporte, 117 trazem al go relacionado ao futebol. Obviamente que esse grau de presença é muito variável, havendo desde breves citações (por exemplo, no recente M orro da Conceição, 2005, de Cristina Grumbach, um dos entrevistados foi jogador; em Ó pera do M alandro, 1985, de Ruy Guerra, há uma cena em um estádio); algum personagem da trama que é jogador (como no caso de Bossa N ova, 2000, de Bruno Barreto; ou 0 Casamento de Louise, 2001, de Betse Paula); passando por aqueles onde o futebol ocupa uma espaço de relativa importância (como no fundamental Rio 40 graus,
1955, Nélson Pereira dos Santos), até aqueles em que é assunto central 3 .

Entre esses últimos, vários são os assuntos abordados: clubes de futebol (caso de Flamengo paixão, 1980, David Neves), Copas do Mundo (por exemplo, Brasil Bom de Bola, 1971, Carlos Niemeyer), jogadores de futebol (caso de 0 Rei Pelé, 1974, Luiz Carlos Barreto e Eduardo Escorel), loteria esportiva (por exemplo, Treze Pontos, 1985, Alonso Gonçalves), questões de gênero (O nda N ova, 1983, José Antônio Garcia), dificuldades da carreira de jogador (A sa Branca, sonho brasileiro, 1981, Djalma Limongi Batista), relações com a política (Prá Frente Brasil, 1982, Roberto Farias), entre muitos outros. Além de documentários, encontramos o futebol em comédias (0 Corintiano, 1966, de Milton Amaral, com Mazzaropi; e 0s Trapalhões e o R ei do Futebol, 1986, Carlos Manga), dramas (Os Trombadinhas, 1979, Anselmo Duarte), policiais (M áscara da Traição, 1969, Roberto Pires), animação (A Turma do Gol, 2000, Paulo Marioti) e até em filmes de sexo explícito (A Pelada do Sexo, 1985, Mário Lúcio).

Entre os cineastas, além dos já citados: Antônio Carlos Fontoura, Carlos Diegues, Carlos Gerbase, Carlos Hugo Christensen, Domingos de Oliveira, Fernando Cony Campos, Glauber Rocha, J. B. Thanko, João Moreira Salles, Joaquim Pedro de Andrade, Leon Hirszman, Luiz de Barros, Maurice Capovilla, Murilo Salles, Oswaldo Caldeira, Ugo Giorgetti, entre muitos outros.

Como não é possível neste artigo comentar todos os filmes brasileiros que tematizaram o futebol, gostaríamos de destacar al guns pelos seu pioneirismo e/ ou importância. Na verdade, o futebol esteve presente nas primeiras películas brasileiras que incorporaram o esporte em sua narrativa.

Por exemplo, em 1931, Genésio Arruda, famoso ator e humorista, dirige Campeão de Futebol, uma homenagem aos jogadores da época. Este foi o primeiro filme nacional de ficção onde o esporte foi efetivamente $o$ assunto central da trama. Na película atuaram muitos atletas famosos à época, como Feitiço e Arthur Friendreich.

Já A Ima e Corpo de uma Raça (1938), dirigido por Milton Rodrigues, um dos irmãos de Nélson Rodrigues, foi produzido por Adhemar Gonzaga e pela Cinédia, um dos mais importantes estúdios do 
cinema brasileiro, responsável por obras-primas de nossa cinematografia e por um de nossos mais conhecidos modelos fílmicos: as chanchadas.

Como locação para este filme, foram utilizadas as dependências do Clube de Regatas do Flamengo. Também foi utilizado o recurso comum de misturar atores profissionais e jogadores de futebol (entre eles Leônidas da Silva). Conta a história de dois atletas que disputam o amor de uma mulher. Esta casará com aquele que der a vitória ao Flamengo. Este foi o primeiro filme diretamente ligado a um clube esportivo. No mesmo ano, Ruy Costa dirigiu Futebol em Família, com o qual estiveram envolvidos importantes nomes do cinema brasileiro: Edgar Brasil (fotografia), Moacyr Fenelon (sonografia) e Wallace Downey (supervisão). No elenco, a tradicional mescla de jogadores (do Fluminense Futebol Clube) e atores (como Grande Otelo e Dircinha Batista). A película narra os problemas de um jovem com os pais, por pretender ser jogador de futebol.

Em 1946 é lançado Gol da Vitória, dirigido por José Carlos Burle, um dos fundadores da Atlântida, estúdio criado no início dos anos 40, responsável pelos mai ores sucessos daquela década. Grande Otelo representou o craque Laurindo, personagem inspirado em Leônidas da Silva.

A Copa do M undo de 1950, dirigido por Milton Rodrigues e produzido por Mário Filho, seu irmão e importante jornalista esportivo, busca os motivos que levaram o Brasil a ser derrotado pelo Uruguai na final daquele evento, em pleno Maracanã. Foi o primeiro documentário cujo tema é o esporte (14). O futebol esteve presente ainda em outros 3 filmes que merecem ser destacados. O primeiro deles é Rio 40 Graus (1955), de Nélson Pereira dos Santos. Ainda que não seja o assunto central da película, ocupa importante espaço em um dos marcos do cinema nacional. De acordo com Alex Viany (15), este filme:

não deixou de dar um novo tom de seriedade ao número ainda pequeno de filmes brasileiros dedicados a temas desportivos, ao mesmo tempo que, fragmentariamente, apresentava uns tantos tipos válidos, como 0 jogador que não mais interessa aos torcedores ( $\mathrm{A} \mid \mathrm{G}$ hiu), o jogador que é lançado no fogo (D omingos Paron), o torcedor completo (Jackson de Souza) e o brigão das gerais (Jece Valadão).
Já Garrincha, A legria do Povo ( 1963) é certamente um dos principais filmes brasileiros e um dos mais importantes que tematizaram o futebol. N omes jovens e destacados do cinema nacional estiveram envolvidos em sua produção: Joaquim Pedro de Andrade (direção e roteiro), Luiz Carlos Barreto (produção), Armando Nogueira (produção e roteiro), Mário Carneiro e David Neves (fotografia). A filme narra a trajetória do jogador, sua capacidade para encantar os fãs com sua personalidade, suas pernas tortas, seus dribles e seu extraordinário tal ento para surpreender os adversários. O documentário intercala depoimentos, trechos de cinejornais e algumas imagens tomadas no Maracanã, sempre procurando situar o aspecto social do futebol no Brasil. A figura de Garrincha é utilizada para traçar um retrato do povo brasileiro, aquele que não tem nada para dar certo, mas, sabe-se lá como, acaba triunfando.

Contudo, esta vitória é parcial, porque os usos de sua imagem tendem a incorporá-lo e apreendêlo ao status quo, em certa medida tirando suas referências, o deslocando de seu papel original, o que deixa poucas opções de sobrevivência ativa. Se o futebol é fator de libertação e de festa, o cineasta também desconfia que possa de ser de alienação e de manipulação, algo que é tematizado de forma sutil e complexa (10). Por fim, Prá Frente Brasil (1982), dirigido por Roberto Farias. Em plena época de abertura política, o filme faz um paral elo entre o envolvimento popuIar com a Copa do Mundo de 1970, na qual o Brasil se sagrou campeão, e as torturas e movimentos de contestação do regime, desconfiando que o futebol possa ser utilizado com ópio do povo. Destacam-se ainda as polêmicas que esse filme desencadeou com a censura à época, o que levou inclusive ao pedido de demissão de Celso Amorim da presidência da Embrafilme (16).

Há ainda duas facetas menos conhecidas do grande público que devem ser levantadas quando falamos da presença do futebol nas telas nacionais. Uma delas são o grande número de imagens documentais que podemos encontrar nos curta-metragens pioneiros do cinema brasileiro e nos cinejornais, programas que eram exibidos antes do filme principal, esportivos (como 0 Esporte em Marcha ou 0 Esporte na Tela) ou não (como Brasil Atualidades ou Notícias da Semana), cujo principal destaque é o já comentado Canal 100. 
Em nossas investigações, encontramos 23 breves filmes documentais sobre o futebol, realizados nas duas primeiras décadas do século XX. Entre eles, destacamos: $M$ atch Internacional de Futebol entre Brasileiros e A rgentinos (1907); Entrega das Taças aos Campeões Paulistas de Futebol (1907), Campeonato de 1908 e M atch de Futebol entre Ingleses e Fluminense (1908); Botafogo, Campeão de Futebol de 1910 (1910); Fluminense Futebol Clube - Fla X Flu (1919) (7).

Para concluir esse item, devemos ainda falar dos muitos curtas-metragens de ficção, cujo número tem sido crescente nos últimos anos. Certamente nesses recentes curtas, alguns também de caráter documental, podemos identificar representações do futebol na sociedade brasileira a partir de suas múltiplas facetas e inter-relações.

Seria impossível aqui resumir o volume e a qualidade dessa produção. Como destaques elencamos U ma História de Futebol (1998, de Paulo Macline), que disputou o Oscar de melhor curta-metragem, e os curtas da Raça Filmes, uma produtora, dirigida por Pedro Asbeg e Felipe N epomuceno, que tem se especializado em captar o futebol a partir de diferentes dimensões e olhares.

\section{PARA TERMINAR: O CINEMA NO FUTEBOL}

Para encerrar o artigo, tratemos de um assunto de grande importância: o cinema (ou a imagem em um sentido mais amplo) teria influenciado na própria dinâmica do futebol? Desde o início o fato concreto é que as relações entre a arte cinematográfica e o esporte tiveram uma dupla dimensão: contribuíram para ampliar o al cance dos espetáculos (tanto esporte quanto cinema) e para ampliar a objetividade na análise dos resultados das competições, já que supostamente bastaria filmar as provas e partidas para que qualquer dúvida fosse sanada.

Há duas questões que precisam ser encaradas. $\mathrm{O}$ uso de imagens é isento de dúvida? Certamente que não e as polêmicas permanecem. Na última Copa do Mundo de Futebol (2002), por exemplo, ficou famoso o episódio em que praticamente todos os jornalistas do mundo afirmaram que o árbitro errara em uma situação polêmica de jogo, fazendo uso para tal de diversas fotografias e takes tomados aproximadamente do mesmo ponto de vista. Até que surge uma foto tirada de outro ângulo, de outro plano, demons- trando que a decisão do árbitro era perfeita. O uso das imagens para melhor observância das regras do espetáculo futebol é al go que desencadeia profícuos debates por todo o mundo.

A segunda questão é que certamente a utilização de imagens, no decorrer do tempo, também trouxe modificações na postura do observador da prática esportiva. Se antes o torcedor dependia basicamente dele mesmo para tomar posicionamentos perante $o$ que estava sendo assistido, a atual utilização de imagens nos espetáculos esportivos acaba por, de alguma forma, retirar um pouco de seu papel definidor, diminuir um pouco o seu papel ativo. $O$ recurso do video-tape e seus desdobramentos (tira-teimas, programas que cal culam "exatamente" o que ocorreu) acabam por ser apresentados como a "verdade", o objetivo, o "científico", deixando a opinião do torcedor para o campo da "doxa".

Não estou afirmando que o uso de imagens "estragou" a prática esportiva, mas a chamar a atenção para as mudanças que foram ocasionadas. Mudanças paulatinas, multifacetadas e cada vez maiores. Como exemplo claro, pode-se lembrar das constantes modificações nas regras de determinados esportes, como no caso do voleibol, para que o jogo se torne mais adequado à transmissão televisiva.

Existe um número enorme de imagens e programas esportivos nas tel evisões de todo o mundo. O esporte é levado para dentro dos lares. Todos têm acesso a um discurso aproximado acerca da prática, mesmo que persistam as polêmicas. Os torcedores são sim ativos, mas lidam com estruturas bastante fortes de convencimento, simultaneamente e em diferentes graus rechaçadas e incorporadas.

O importante é entender que a possibilidade de difusão rompeu o limite claro entre o público e o privado, envolveu ainda mais mulheres, famílias, filhos (algo que já era observável anteriormente nas instalações esportivas), mas estabeleceu um acesso mediado pel os "especialistas" a partir de uma idéia de objetividade.

Enfim, como um caminho de via dupla, cinema e futebol se inter-influenciaram e dialogaram constantemente. $E$ esse percurso nos permite vislumbrar uma possibilidade de compreender os discursos acerca da sociedade, determinadas representações, certos mitos. Estar atento a isso, como recurso de 
investigação, como possibilidade pedagógica ou como maneira de ampliar nosso prazer, é uma necessidade e um desafio para todos nós, pesquisadores, estudiosos, interessados ou fãs.

\section{AGRADECIMENTOS}

Ao Conselho Nacional de Pesquisa (Brasil) e à Fundação de Amparo à Pesquisa do Estado do Rio de Janeiro, pelo financiamento à essa investigação.

\section{CORRESPONDÊNCIA}

\section{Victor A. de Melo}

Universidade Federal do Rio de Janeiro

Praia de Botafogo, 472/810 - Botafogo

Rio de Janeiro - RJ

Brasil

CEP: 22250-040

victor.a.melo@uol.com.br

\section{REFERÊNCIAS}

1. Melo VA, Peres FF (2005). 0 esporte vai ao cinema. Rio de Janeiro: Editora do Senac.

2. Melo VA (2004). Esporte, imagem, cinema: diálogos. Relatório de pesquisa/pós-doutorado em Estudos Culturais. Rio de Janeiro: Programa Avançado de Cultura Contemporânea. Disponível em: http:// www.lazer.eefd.ufrj.br/cinema.

3. Debord G (1997). Sociedade do espetáculo. Rio de Janeiro: Contraponto.

4. González JM (2003). Evasión o victoria. Nickel Odeon 33:130.

5. Melo VA (2005). O esporte como uma forma de arte: diálogos entre (duas?) linguagens. M ovimento 11(2): 35-55.

6. Caldeira O (2005). Garrincha, Alegria do Povo - futebol, tema de filme? In: Melo VA, Peres FF (orgs.). 0 esporte vai ao cinema. Rio de Janeiro: Editora do Senac, 39-52.

7. Melo VA (2005). Esporte e cinema: diálogos - as primeiras imagens brasileiras. Rev.Bras.Cienc. Esporte 26(2): 21-38.

8. Ramió JR (2003). Presencia del deporte em el cine español. Madrid: Fundación Andalucia Olímpica y Consejo Superior de Deportes.

9. González JM (2003). Evasión o victoria. Nickel Odeon 33:133.

10. Melo VA (2006). Eficiência x jogo de cintura: Garrincha, Pelé, Nélson Rodrigues e a construção da identidade nacional. In: Silva FCT (org.). Memória Social do Esporte 2. Rio de Janeiro: Mauad, 56-78.

11. González JM (2003). Evasión o victoria. Nickel Odeon 33:131.

12. Rocha G (2003). Revisão Crítica do cinema brasileiro. São Paulo Cosac \& Naif:149.

13. Melo VA (2003). Memórias do esporte no cinema brasileira: sua presença em longa-metragens brasileiros. Rev.Bras.Cienc.Esporte 25(1): 37-52.

14. Murad M (1999). Futebol e cinema no Brasil 1908/1998. In: Costa M (org.). Futebol: espetáculo do século. São Paulo: Musa Editora, 26-38.

15. Viany A (1967). Cinema no Maracanã. In: Pedrosa M (org.). Gol de letra: o futebol na literatura brasileira. Rio de Janeiro: Editora Gol, 1967, 127.

16. Silva FCT (2005). Futebol e Política: Prá Frente Brasil. In: Melo VA, Peres FF (orgs.). 0 esporte vai ao cinema. Rio de Janeiro: Editora do Senac, 21-20.

1 Um exemplo disso é o recentemente lançado Pelé Eterno (2004, Anibal Massaini Neto).

2 Não surpreende que a FIFA tenha lançado, no ano de 2005, o DVD Fifa Fever: 0 M elhor da História do Futebol, com o intuito de comemorar o centenário da instituição (1904-2004), com imagens documentais de Copas do Mundo.

3 Uma lista completa de todos os filmes brasileiros que tematizam o esporte, bem como dos específicos de futebol, pode ser encontrada em: www.lazer.eefd.ufrj.br/ esportearte. 